\title{
Durch den Sertão von Guimarães Rosa
}

\section{Bericht einer Wanderung und Kommentar seines Romans}

Der Sertão ist seit 1960, als in dieser Region die neue Hauptstadt Brasília eingeweiht wurde, das geographische Zentrum der Politik in Brasilien. Schon vorher hatte diese auf der zentralen Hochebene gelegene Busch- und Steppen-Landschaft zwei der bedeutendsten Schriftsteller, Euclides da Cunha (1866-1909) und João Guimarães Rosa (1908-1967), dazu inspiriert, zwei grundlegende Brasilienbilder zu verfassen: Os Sertões (1902; deutsch: Krieg im Sertão, 1994), ein Bericht des Kampfes der Armee gegen die Aufständischen von Canudos in den Jahren 1896/1897, und den Roman Grande sertão: veredas (1956; deutsch: Grande Sertão, 1964). Der Leser dieses Romans steht vor einer doppelten Herausforderung: Die bewusst schwierige Komposition und Sprache dieses Werkes zu verstehen, und sich in der komplexen Topographie des Sertão von Minas Gerais zurechtzufinden, den der Protagonist und Erzähler Riobaldo in der Zeit um 1900 etliche Male durchquert hat.

Der vorliegende Aufsatz möchte dem Leser bei dieser Durchquerung des Sertão in dreifacher Hinsicht behilflich sein: 1) Ein Überblick über die Komposition und ein Resümee der Handlung bieten eine Einführung in den Roman; außerdem werden auf einer Karte die wichtigsten Handlungsorte vorgestellt. 2) Von der Lektüre des Werkes gehen wir über zum realen Sertão von Minas Gerais, speziell zum Gebiet des Urucúia-Flusses und der Serra das Araras, die zu den wichtigsten Schauplätzen der Romanhandlung gehören. Um eine konkrete Vorstellung davon zu vermitteln, berichte ich von der Erfahrung einer kollektiven im Juli 2017 unternommenen Wanderung durch diese Region. 3) Vom realen Sertão kehren wir zurück zum Roman, um anhand von markanten Orten und Momenten unserer Durchquerung einige der Hauptthemen zu kommentieren. $\mathrm{Zu}$ diesen gehören insbesondere das Jagunço-System, d. h. das Treiben von kriminellen Banden, die auf der zentralen Hochebene des Landes die Macht ausüben. Speziell wird auch der Pakt des Erzähler-Protagonisten mit dem Teufel analysiert, der mit dem scheinbar blasphemischen Projekt des Autors Guimarães Rosa verbunden werden kann, eine neue Sprache zu erschaffen bzw. zumindest die in Brasilien gebräuchliche Sprache neu zu erfinden. Wie gezeigt wird, handelt es sich um eine Vermittlungsarbeit des Schriftstellers, der mit Hilfe einer radikalen Erneuerung der Sprache versucht, die diabolische Situation eines fehlenden Dialogs zwischen der Klasse der Gebildeten und dem einfachen Volk zu überwinden. 


\section{Die reale und die fiktionale Topographie des Romans}

Karte 1 soll dem Leser eine Einführung in die reale und fiktionale Topographie des Romans Grande sertão: veredas bieten. Die in diesem Werk erzählte Geschichte ereignet sich im Norden des Bundesstaates Minas Gerais, jenseits der Kleinstädte Curvelo und Corinto, hinter denen bereits der Sertão beginnt. Die geographische Hauptachse dieser Region ist der Rio São Francisco mit seinen Nebenflüssen; im Osten: Rio-de-Janeiro, Rio das Velhas, Jequitaí, Rio Verde Grande; und im Westen: Rio Abaeté, Paracatu, Urucúia und Carinhanha. Auch einige Städte werden erwähnt, wie São Romão, São Francisco, Januária, Montes Claros und Brasília (de Minas); die städtischen Gebiete wurden jedoch von den Jagunços in der Regel gemieden.

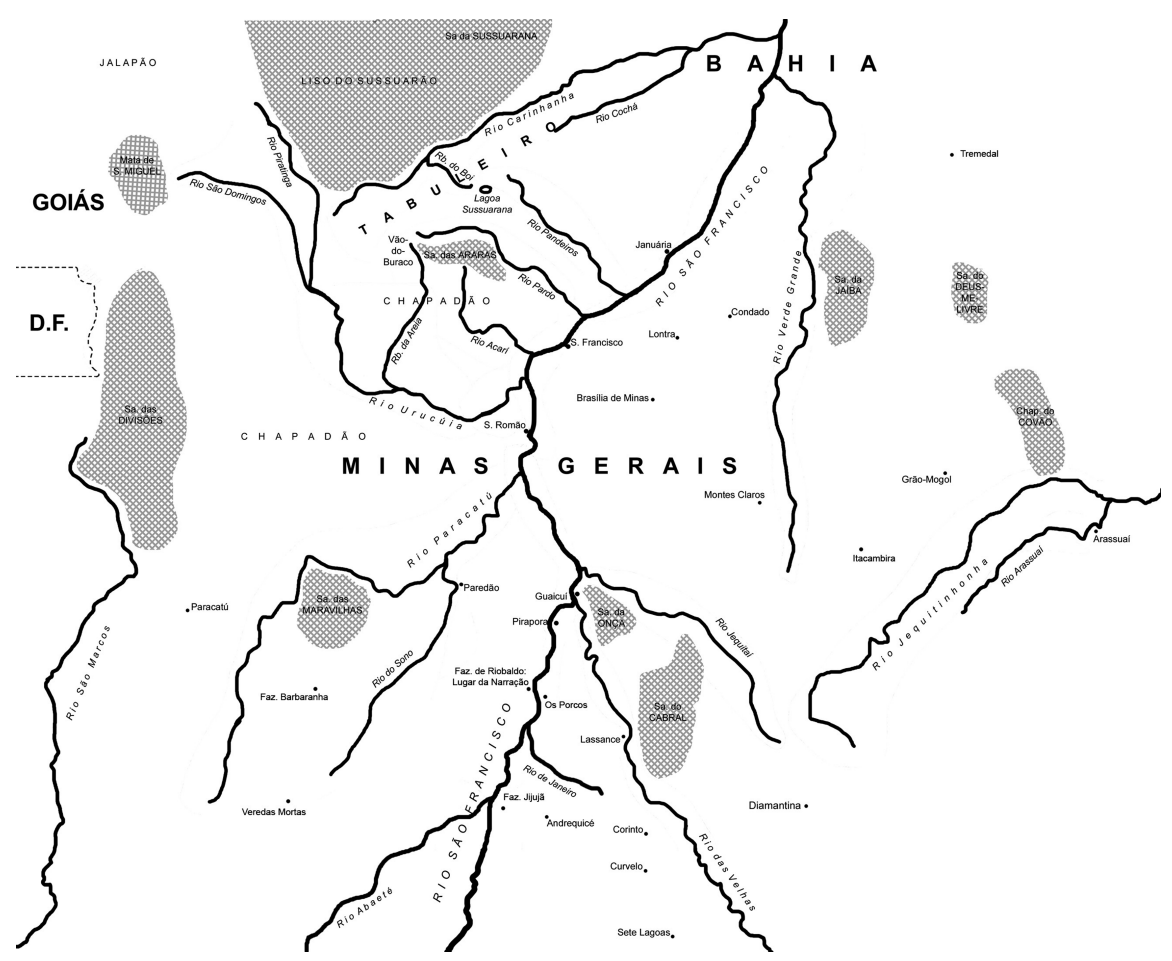

Karte 1: Reale und fiktionale Topographie von Grande sertão: veredas

Reale und fiktionale Ortsnamen wechseln in diesem Roman einander ab, wie bereits Antonio Candido (1957) bemerkt hat. In seiner Studie Itinerário de Riobaldo 
Tatarana (1974) hat Alan Viggiano gezeigt, dass von den 230 vom Erzähler genannten Ortsnamen mehr als 180, also $78 \%$, in der geographischen Wirklichkeit existieren. Es handelt sich um Angaben wie Curralinho (der ehemalige Name von Corinto), Arrassuaí (der Fluss und die Ortschaft), die Stadt Januária, die Serra das Araras, die Flüsse Urucúia und Carinhanha und der Ort Paredão. Andere Plätze hingegen sind erfunden, wie die Fazenda von Riobaldo (der Ort der Erzählung) oder die Veredas Mortas, die toten Fließe (wo der Protagonist den Pakt mit dem Teufel geschlossen hat). Und noch andere, speziell die Sussuarão-Wüste, sind das Ergebnis einer Montage von Fragmenten der Realität mit Elementen literarischer Erfindung. ${ }^{1}$

Riobaldo erzählt seine Geschichte gegen Ende der 1920er Jahre. Die erzählte Geschichte trug sich etwa drei Jahrzehnte vorher zu, in den Jahren um 1900. Damals war der Bau der Eisenbahnlinie bis an den Beginn des Sertão noch in der Planung, die Transportmittel waren Pferde und Maultiere. Der Sertão, als Gebiet weitflächiger Viehzucht, mit Fazendas, deren Besitzer Jagunços zur Verfügung hatten, galt als eine rückständige, unterentwickelte und gefährliche Region.

\section{Kompositions-Einheiten und Handlung}

Bevor wir uns den verschiedenen Orten näher zuwenden, soll gezeigt werden, wie sie im Kontext des Werkes erscheinen. Der Roman ist ein Erzählfluss von mehr als 500 Seiten, ohne Untergliederung in Kapitel. Es lassen sich jedoch sieben Kompositions-Einheiten identifizieren. In vier von ihnen (siehe die Punkte 1, 3, 5 und 7) steht die Erzählsituation im Vordergrund, d.h. die Art und Weise, wie die Geschichte dargestellt wird; bei den übrigen drei (Punkte 2, 4 und 6), handelt es sich um den Inhalt der erzählten Geschichte. Im Einzelnen sieht das so aus:

2.1 Im Proömium ${ }^{2}$ werden die Erzählsituation und der Ort des Erzählens vorgestellt. Der Fazendeiro und ehemalige Jagunço Riobaldo gibt seinem Besucher, einem Gebildeten aus der Stadt, eine Einführung in die Welt des Sertão, indem er ihm verschiedene Geschichten aus dieser Region erzählt. Die Fazenda liegt am linken Ufer des Rio São Francisco, in der Kontaktzone zwischem dem Sertão und der Zivilisation, die von den Kleinstädten Sete Lagoas, Curvelo, Corinto und Andrequicé verkörpert wird.

1 Auf den Karten 2, 3 und 5 kann der Weg des Protagonisten weitgehend in Anlehnung an die reale Geographie nachvollzogen werden. Da es sich jedoch um ein Werk der Fiktion handelt, gibt es freilich auch Stellen, an denen wir auf Vermutungen angewiesen sind.

2 João Guimarães Rosa: Grande Sertão. Übersetzung: Curt Meyer-Clason. Köln: Kiepenheuer \& Witsch 1964, S. 11-32. 
2.2 Riobaldo beginnt die Erzählung seines Lebens als Jagunço mit einem Ausschnitt in medias res. ${ }^{3}$ Es ist eine Durchquerung des Sertão in alle Himmelsrichtungen. Nach Norden vom Tafelland des Urucúia in Richtung der Sussuarão-Wüste. ${ }^{4}$ Anschließend nach Westen bis hinein in den Bundesstaat Goiás. Dann nach Osten bis zu den Edelstein-Minen am Fluss Arassuaí und schließlich eine Rückkehr nach Westen bis zum Urucúia mit einem Ritt in Richtung Süden zur Fazenda São Serafim. Bereits hier lässt sich feststellen, was durch den weiteren Verlauf der Erzählung bestätigt wird: nämlich, dass die zentralen Handlungsorte sich in der Region des Urucúia-Flusses befinden. Dieses Gebiet ist bis heute das ärmste von Minas Gerais, im Gegensatz zu den anderen Teilen dieses Bundesstaats, in denen Bergbau und Industrie vorherrschen.

2.3 Es kommt zu einer Unterbrechung der Erzählung ${ }^{5}$; Riobaldo spricht von den Schwierigkeiten des Erzählens und setzt zu einem Neubeginn an, indem er sein Leben nunmehr in chronologischer Folge schildert.

2.4 Der erste Teil von Riobaldos Lebensgeschichte. ${ }^{6}$ Ein Vorfall, der sein Leben entscheidend geprägt hat, war in frühen Jahren die Begegnung mit dem Jungen (Diadorim), mit dem er den Rio São Francisco an der Einmündung des Riode-Janeiro überquert hatte. Nachdem Riobaldo seine Jugendjahre auf der Fazenda seines Vaters verbracht hat, währenddessen er auch in dem Ort Corinto die Schule besuchte, arbeitet er zeitweilig als Lehrer und Sekretär von Zé Bebelo, der eine Karriere als Politiker anstrebt und sich deswegen als Beseitiger des Jagunçotums einen Namen machen will. Die Wiederbegegnung mit dem Jungen, der sich als der Jagunço Reinaldo vorstellt, bewegt Riobaldo dazu, in die Bande von Joca Ramiro einzutreten. Beide zusammen durchqueren den wilden Norden auf der östlichen Seite des Rio São Francisco. Die Ermordung des Jagunçoführers Joca Ramiro durch die Verräter Hermógenes und Ricardão löst einen Krieg zwischen den Banden aus, der erst am Schluss des Romans sein Ende findet.

2.5 Es kommt zu einer zweiten Unterbrechung der erzählten Geschichte ${ }^{7}$ und zu einem Neuansatz. Riobaldo berichtet seinem Zuhörer nunmehr von seinen «Fehlern» und seiner «Schuld». Die Bezugnahme auf den Rio São Francisco, der das Leben des Protagonisten «in zwei Teile geteilt hat», wurde in den ersten Auflagen des

3 Ebda., S. 32-94.

4 Die Sussuarão-Wüste ist dem Erzähler zufolge "gute fünfzig Léguas lang und fast dreißig breit» (Rosa: Grande Sertão, S. 459), d.h. sie hat eine Ausdehnung von etwa 300 und 180 km. Eine Wüste von dieser Größe gibt es in dieser Region nicht, wie ich während einer Expedition im Jahre 1998 vor Ort festgestellt habe.

5 Ebda., S. 94-96.

6 Ebda., S. 96-287.

7 Ebda., S. 287-290. 
Buches auch durch die graphische Aufmachung veranschaulicht: auf den Buchklappen rechts und links befanden sich zwei einander ergänzende Landkarten mit den Handlungsorten, wobei der in der Mitte liegende Verlauf des Flusses São Francisco von den Seiten des Erzählflusses von Riobaldo überlagert wurde.

2.6 Riobaldo setzt seine Geschichte an der Stelle fort, an der er sie in dem anfänglichen Ausschnitt unterbrochen hatte und berichtet nun vom zweiten Teil seines Lebens als Jagunço. ${ }^{8}$ Von der Fazenda São Serafim reitet die Bande durch das Tafelland des Urucúia nach Süden bis nach Sucruiú, ein Ort des Elends. Bei den Veredas Mortas schließt Riobaldo einen Pakt mit dem Teufel. Er übernimmt das Kommando der Bande und praktiziert das Jagunço-System. Mit seinen Leuten durchquert er die Sussuarão-Wüste und macht einen Überraschungsangriff auf die Fazenda des Hermógenes, dessen Frau als Geisel mitgenommen wird. Nach einem strategischen Umweg durch den Bundesstaat Goiás kehrt die Bande nach Minas Gerais zurück. An dem Ort Paredão findet die entscheidende letzte Schlacht statt, wobei Hermógenes und Diadorim in einem Duell den Tod finden.

2.7 Im Epilog 9 erscheint Riobaldo auf seiner Fazenda als ein mächtiger, von seinen Jagunços beschützter Großgrundbesitzer. Immer wieder kommen ihm die Erinnerungen an entscheidende Orte seines Lebens, wie die Veredas Mortas, zusammen mit den Gedanken an Diadorim und den Pakt mit dem Teufel.

\section{Der erste Teil der Geschichte Riobaldos}

Gehen wir nun dazu über, uns mit der Topographie des Sertão genauer vertraut zu machen, was anhand der Karte 2 geschehen soll, die den ersten Teil von Riobaldos Lebensgeschichte resümiert. Nahezu alle Handlungsorte liegen auf der Ostseite des Rio São Francisco. Die erste Episode allerdings, die für den weiteren Lebensweg Riobaldos von entscheidender Bedeutung sein sollte, trug sich genau in der Mitte dieses Flusses zu, während seiner Überquerung. Es war das Zusammentreffen des heranwachsenden Riobaldo mit dem Jungen (Diadorim), an der Stelle, wo der Riode-Janeiro in den São Francisco einmündet (siehe auf der Karte den Punkt 0). Die Überquerung dieses Flusses in Begleitung des Jungen war für Riobaldo ein Initiationsritual, bei dem drei Gefühle zusammenwirken: Liebe, Angst und Mut. - Im Anschluss an diese Begebenheit werden drei Folgen von Episoden erzählt.

3.1 Riobaldos hatte einen ersten Kontakt mit der Welt der Jagunço durch die Geschichten, die sein Vater, Selorico Mendes, auf der Fazenda São Gregório* (1)

8 Ebda., S. 290-544.

9 Ebda., S. 544-550. 
erzählte. ${ }^{10}$ Ihre Wirkung wurde durch das plötzliche Erscheinen einer Bande unter dem Chef Joca Ramiro verstärkt, der um eine Übernachtung auf der Fazenda ersuchte. Wenig später flieht der junge Riobaldo aus dem Haus seines Vaters in das Städtchen Corinto (2), wo er die Schule besucht und sich als ein außergewöhnlich begabter Schüler hervorgetan hatte. Sein Lehrer lud ihn ein, beim Unterricht mitzuhelfen und «den Jüngeren das Lesen und Schreiben beizubringen» (GS, S. 108). ${ }^{11}$ Von seiner viel versprechenden Karriere als Lehrer in einer öffentlichen Schule wird Riobaldo jedoch durch ein Angebot abgelenkt, das er von dem Besitzer der Fazenda Nhanva* (4) erhält. Es handelt sich um Zé Bebelo, der ein hohes politisches Amt anstrebt und dazu auch eines Lehrers und Sekretärs bedarf. Der Slogan seiner Werbekampagne ist «die Abschaffung des Jagunçotums». $\mathrm{Zu}$ diesem Zweck hat er eine Truppe von Soldaten engagiert, mit der sich Riobaldo nunmehr in den «wilden Norden» begeben muß. Nachdem die Truppe im Munizip von Brasília (6) einen Sieg über die Bande des Hermógenes errungen hat, fordert Zé Bebelo seinen Sekretär Riobaldo auf, eine Werberede für ihn zu halten. Zwischen den Orten Lontra und Condado (7) gelingt der Truppe ein weiterer Sieg, diesmal über die Bande von Ricardão. Als sie dann in Richtung Grão-Mogol (8) weiterziehen, entschließt sich Riobaldo, dem dieses ständige brutale Vorgehen zuwider ist, Zé Bebelo und seine Truppe zu verlassen. Nach einem Ritt von mehreren Tagen (9) erreicht er schließlich den Rio das Velhas.

3.2 An dem Nebenfluss Córrego do Batistério (10) trifft Riobaldo durch Zufall den Jungen wieder, der nun schon erwachsen ist und sich als der Jagunço Reinaldo, im Dienst von Joca Ramiro vorstellt (und der ihm später seinen geheimen Namen Diadorim anvertrauen wird). Wegen der Anziehung, die Reinaldo auf ihn ausübt, entschließt sich Riobaldo, in die Bande einzutreten. Unter dem Kommando des Unterführers Titão Passos reiten sie nach Norden (11) und vereinen sich in der Mata da Jaíba (12) mit der Bande des Hermógenes. Unter dessen Führung, der den Ruf eines Teufelspaktierers hat, führt Riobaldo seinen ersten Kampf als Jagunço und wird dabei in die Praxis des Tötens eingeführt. Auf der Chapada-da-Seriema-Correndo* (15) erreichen sie einen Sieg über die Truppe von Zé Bebelo. Dieser wird gefangen genommen und auf der Fazenda Sempre-Verde` (16) vor ein Tribunal gestellt, das von dem obersten Chef Joca Ramiro geleitet wird und an dem auch alle Unterführer

10 Die für die Romanhandlung wichtigsten Orte werden auf dieser Karte mit den Nummern 1 bis 26 angegeben. Während diese topographischen Angaben in meinem Buch grandesertão.br vollständig kommentiert werden, habe ich in diesem Aufsatz eine Auswahl getroffen. Die vom Erzähler erfundenen Orte sind im Text mit dem Zeichen * markiert.

11 Die Abkürzung GS (= Grande Sertão) bezieht sich auf die deutsche Übersetzung (1964) von Curt Meyer-Clason. In den Zitaten habe ich manchmal kleine stilistische Veränderungen vorgenommen. 
teilnehmen. Mit einer Reihe von Diskursen der Anklage und der Verteidigung ist diese Episode eine der wichtigsten des Romans, denn sie zeigt, dass sich das Jagunçotum auch auf ein rhetorisches und juristisches System sui generis stützen kann. Das Urteil endet mit der Freisprechung Zé Bebelos, der jedoch den Staat Minas Gerais verlassen muss. Unter dem Kommando von Titão Passos zieht die Bande mit Riobaldo und Diadorim am Ufer des Rio São Francisco entlang (17) nach Süden bis zu einem Ruheplatz namens Guararavacã do Guiaicuí (18).

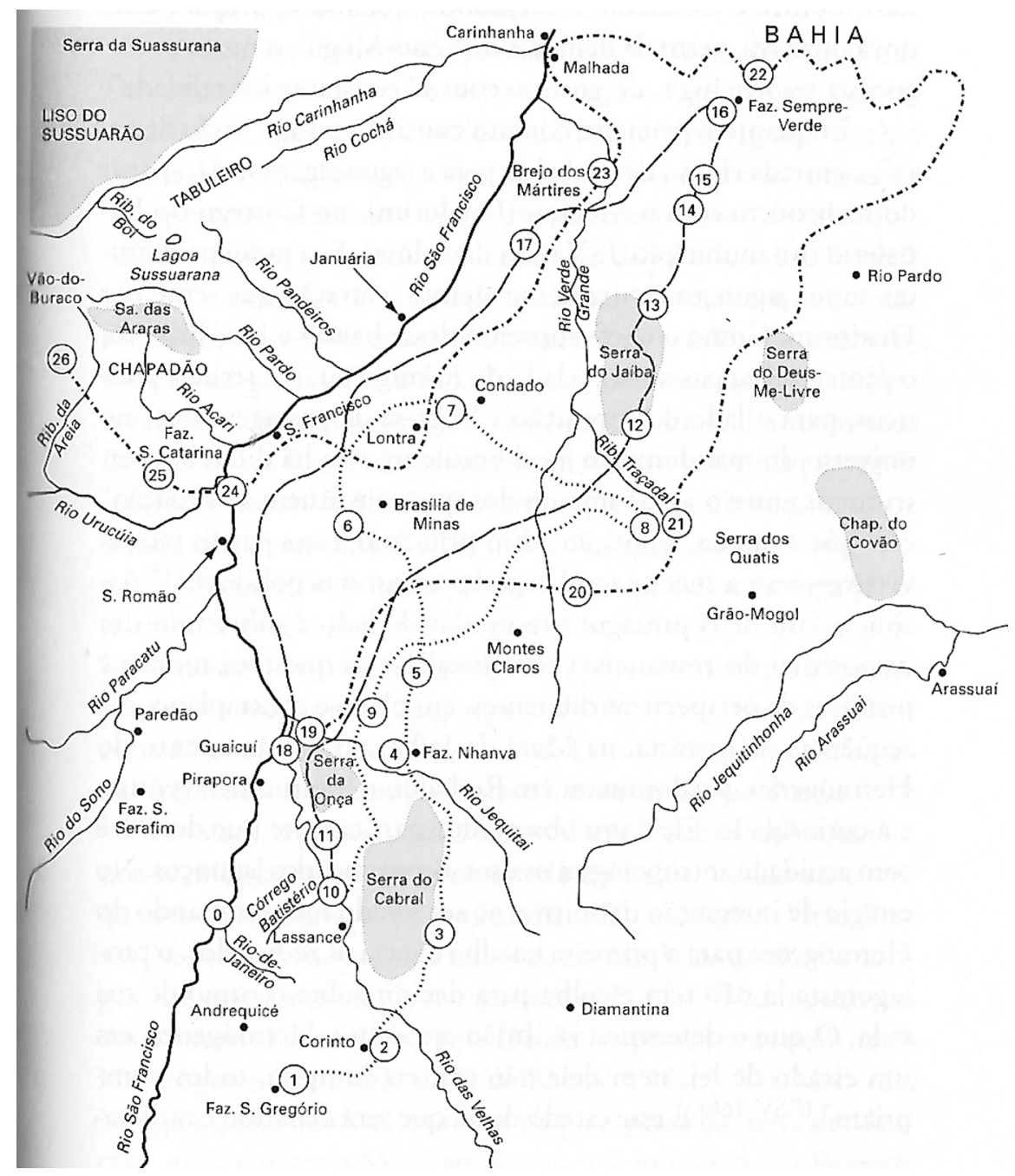

Karte 2: Topographie des Jagunçotums: der erste Teil der Geschichte Riobaldos 
3.3 An diesem idyllischen Ort erhalten die Mitglieder der Bande eine schreckliche Nachricht: Ihr oberster Chef Joca Ramiro ist von den Unterführern Ricardão und Hermógenes ermordert worden. Diese hatten den Tod von Zé Bebelo gefordert und waren empört darüber, dass man ihn freigelassen hatte. Nun beginnt ein weiterer Krieg, diesmal gegen die Verräter. Am Rio Verde Grande (20) gelingt es den «Judassen», nach Westen zu entkommen, während die Bande von Riobaldo und Diadorim von Soldaten angegriffen und verfolgt wird (21). Auf der Flucht überschreiten sie mehrere Male die Grenze zwischen Minas und Bahia (22). Danach begibt sich eine kleine Gruppe mit Riobaldo und Diadorim über Malhada und Brejo dos Mártires (23) nach Süden. Sie überqueren den São Francisco nahe der Mündung des Urucúia (24). In diesem Gebiet, auf der Fazenda Santa-Catarina* (25), lernt Riobaldo die Tochter eines Fazendeiro, Otacília, kennen, der er seine Heiratspläne zu erkennen gibt. Zunächst jedoch ziehen Riobaldo und Diadorim weiter bis zum Hochland des Urucúia (26) und schließen sich dort der Bande von Medeiro Vaz an. - Hier erfolgt die zweite Unterbrechung der Erzählung. In der Folge wird Riobaldo dann von seiner «Schuld» und seinen «Fehlern» berichten.

\section{Der letzte Teil der Geschichte Riobaldos}

Alle Handlungsorte dieses Teils von Riobaldos Geschichte befinden sich auf der westlichen Seite des Rio São Francisco (siehe Karte 3). - Es lassen sich vier Sequenzen von Episoden unterscheiden.

4.1 Unter dem Kommando von Zé Bebelo - der aus opportunistischen Gründen von einem Verfolger zu einem Verbündeten der Jagunços geworden ist zieht die Bande mit Riobaldo und Diadorim von der Fazenda São Serafim* (1) in Richtung Norden. Auf der Fazenda dos Tucanos* (3) werden sie von der feindlichen Bande des Hermógenes umzingelt. Zé Bebelo versucht daraufhin, Kontakt mit den Soldaten der Regierung aufzunehmen, dieser Versuch eines Verrats wird jedoch von Riobaldo vereitelt.

4.2 Es gelingt Riobaldo, mit Zé Bebelo und den Kumpanen nach Westen zu fliehen (4). Im Tafelland des Urucúia (5) beschaffen sie sich neue Pferde. Beim Weitermarsch verirren sie sich im Sertão (7). Die Möglichkeit, den Weg der Bande kartographisch zu bestimmen, stößt hier an eine Grenze. Wie der Erzähler erklärt, hatte ihr Führer sie statt nach dem Ort Virgem-Mãe nach Virgem-da-Lage fehlgeleitet. Diese Verwechslung und topographische Ungenauigkeit sind von der Komposition des Romans her beabsichtigt: sie vermitteln den Eindruck von einem Labyrinth. Auf dem Weg nach Süden gelangen die Jagunços zu entscheidenden Orten der Handlung, wobei sämtliche Namen erfunden sind: die Dörfer Pubo* (8) und Sucruiú ${ }^{\star}$ (9), mit den unter ärmsten Verhältnissen lebenden Catrumanos, so- 
wie die Güter Valado* und Coruja` (10), Besitztümer des Fazendeiros Seô Habão. Die Begegnung mit diesem Großgrundbesitzer, der die Sertanjos aufs Äußerste ausbeutet und zu verstehen gibt, dass er sich auch Riobaldo und seine JagunçoGefährten als Tagelöhner bzw. Leibeigene zunutze machen will, ist für den Protagonisten der entscheidende Anlass, einen Pakt mit dem Teufel zu schließen, was an dem Ort Veredas Mortas* (11) geschieht.

4.3 Vor der gesamten Bande stellt Riobaldo die Führerrolle von Zé Bebelo in Frage und übernimmt das Kommando. Die Jagunço ziehen erneut in Richtung Norden, zum Tafelland des Urucúia (15). Nachdem sie den Urucúia-Fluss (18) überquert haben, reiten sie am Ribeirão da Areia (19) entlang bis zur Serra das Araras (20) und von dort bis zum Quellgebiet des Rio Carinhanha (21). Hier nun enthüllt Riobaldo seinen strategischen Plan: die Sussuarão-Wüste* (22) zu durchqueren, um einen Überraschungsangriff auf die jenseits der Wüste, am Rio das Fêmeas liegende Fazenda des Hermógenes ${ }^{\star}$ (23) durchzuführen. Diesmal gelingt die Durchquerung der Wüste, und auf der Fazenda des Feindes nehmen Riobaldos Jagunços die Frau des Hermógenes als Geisel mit. 


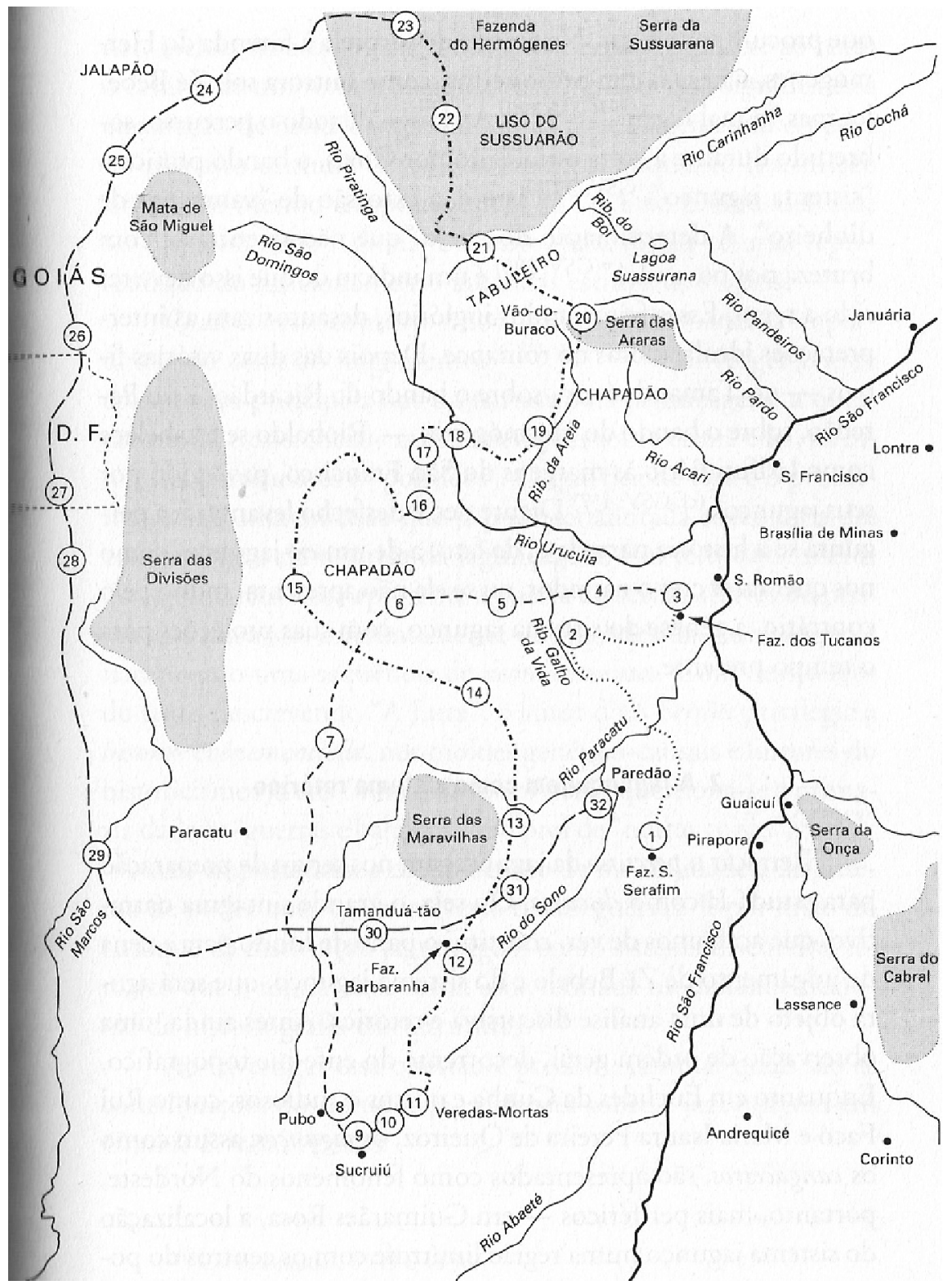

Karte 3: Topographie des Jagunçotums: der letzte Teil der Geschichte Riobaldos

4.4 Im letzten Teil ihrer Durchquerung des Sertão macht die Bande einen strategischen Umweg: von der Fazenda des Hermógenes, im äußersten Westen von Bahia durch den Nachbarstaat Goiás. Sie durchqueren die Gegend von Jalapão (24) so- 
wie das Gebiet, in dem Jahrzehnte später der Bundesdistrikt und die neue Hauptstadt Brasília (27) enstehen werden; sie umgehen die Serra das Divisões (28), überqueren den Rio São Marcos (29) und kehren zurück in den Staat Minas Gerais. Auf dem Weiterritt nach Osten gelingt es Riobaldo und seinen Jagunços, in der Ebene von Tamanduá-tão (30) die Bande des Ricardão zu besiegen; und beim Weitermarsch in Richtung des Rio do Sono erringt er bei der Ortschaft Paredão (32) den endgültigen Sieg über den Hermógenes. Bei dieser letzten Schlacht kommt der Chef Riobaldo allerdings verspätet an, weil er sich zeitweilig von seiner Bande entfernt hatte, um seine Braut zu treffen. Das daraus entstandene Schuldgefühl wird ihn sein Leben lang begleiten, denn als er am Ort der Schlacht ankommt, kann er nicht verhindern, dass Diadorim den Hermógenes zu einem Duell herausfordert, in dem beide den Tod finden. Als sie ihm die Leiche des Jagunços Reinaldo bringen, dessen geheimer Name Diadorim war, entdeckt Riobaldo, dass die große Leidenschaft seines Lebens kein anderer Mann war, wie er immer geglaubt hatte, sondern eine Frau, ein Mädchen «von vollkommener Schönheit».

\section{Vom Roman in die Realität des heutigen Sertão: unsere Wanderung im Juli 2017}

Seit 2014 hat eine im Munizip von Arinos (Minas Gerais) gegründete NGO, die Agentur für die integrierte und nachhaltige Entwicklung des Urucúia-Tals (Agência de Desenvolvimento Integrado e Sustentável do Vale do Urucúia), eine «sozio-öko-literarische Wanderung» organisiert, die alljährlich im Monat Juli stattfindet, eine Woche dauert und an der 50 bis 80 Wanderer teilnehmen. ${ }^{12}$ Diese Durchquerung des Sertão ist hauptsächlich vom Werk Guimarães Rosas inspiriert, wie schon der Name der in den 1970er Jahren gegründeten Siedlung Sagarana zeigt, die den Titel seines Erstlingswerks übernommen hat. Hier beginnt die Wanderung, die uns bis zum Urucúia-Fluss führte und von dort zum Ribeirão da Areia und in die Serra das Araras. Nachdem wir $178 \mathrm{~km}$ zu Fuß zurückgelegt hatten, kamen wir schließlich am Eingang des Nationalparks Grande sertão: veredas an, der sich wenige Kilometer hinter dem Städtchen Chapada Gaúcha befindet (siehe Karte 4). Im Jahre 2017, im Gedenken an den 50jährigen Todestag von Guimarães Rosa, wurden die Wanderer von einem Team des Fernsehsenders GloboNews begleitet, das die Erfahrung dieser Durchquerung des Sertão in dem Dokumentarfilm Sertanías aufzeichnete, der

12 Siehe die Website http://www.ocaminhodosertao.wordpress.com. Letzter Zugriff: 30.1.2018. 
am 19.11.2017 ausgestrahlt wurde. ${ }^{13}$ Von der Regisseurin des Films, der Nichte von Guimarães Rosa, wurde ich eingeladen an der Wanderung teilzunehmen. Am Vorabend trafen wir in der Siedlung Sagarana ein, wo wir Kontakt mit den Veranstaltern und der Gruppe der Wanderer aufnahmen, der vor allem Lehrer, Forscher, Künstler sowie allgemein Interessierte angehörten. Ich berichte nun von der Erfahrung unser sieben Tage dauernden Durchquerung des Sertão.

1. Tag: Von Sagarana bis Morrinhos, am Ufer des Rio Urucúia. Wir pflegten in Zelten zu übernachten und standen jeden Tag frühmorgens um 4 Uhr auf. Nachdem wir die Zelte abgebaut und unser Frühstück eingenommen hatten, machten wir uns beim Anbruch des Tages auf den Weg. Wir wurden von ortsansässigen Führern und von einigen Autos begleitet, die Wasser, Nahrungsmittel, die Zelte und andere Gepäckstücke transportierten. Auch ein Sanitätswagen war mit dabei. Kurz nachdem wir die Ortschaft Sagarana verlassen hatten, befanden wir uns schon mitten im Cerrado, dem für diese Region typischen Wald mit einer Vielfalt von niedrigen und stark verästelten Bäumen.

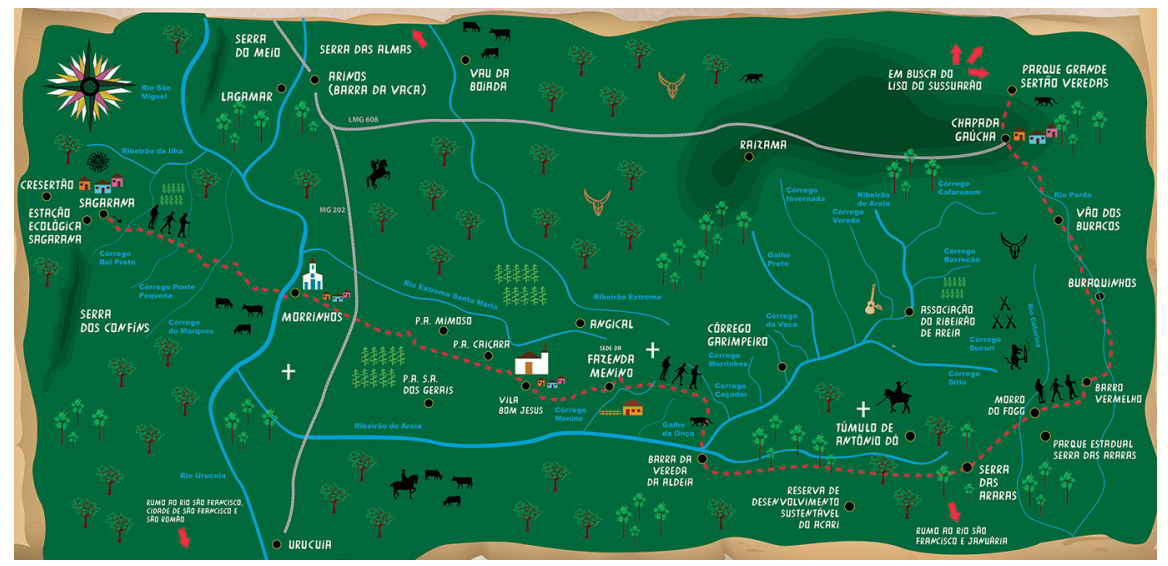

Karte 4: Route der Wanderung. Von der Siedlung Sagarana zum Naturschutzgebiet Grande sertão: veredas

Dazwischen liegen Fluren von wildem Gras, die der Landschaft ein steppenähnliches Aussehen verleihen. Nachdem wir $33 \mathrm{~km}$ zurückgelegt hatten, mit einer Pause zum Mittagessen, erreichten wir am späten Nachmittag den Rio Urucúia

13 Regie und Drehbuch des Dokumentarfilms Sertanías (54 Minuten): Juliana Dametto Guimarães Rosa und Alexandre Roldão; Kameramann: Sandiego Fernandes. Siehe die Reportage von Gustavo Fioratti in der Folha de S. Paulo (16.11.2017), S. C 1. 
(Abb. 1). Er ist der Lieblingsfluss des Protagonisten von Grande sertão: veredas: «Den Urucúia liebe ich besonders», erklärt Riobaldo (GS, S. 70), der ihn auch mit der Erinnerung an Diadorim verbindet. Wir überquerten den Fluss auf einer Fähre und übernachteten auf dem anderen Ufer, in der Ortschaft Morrinhos.

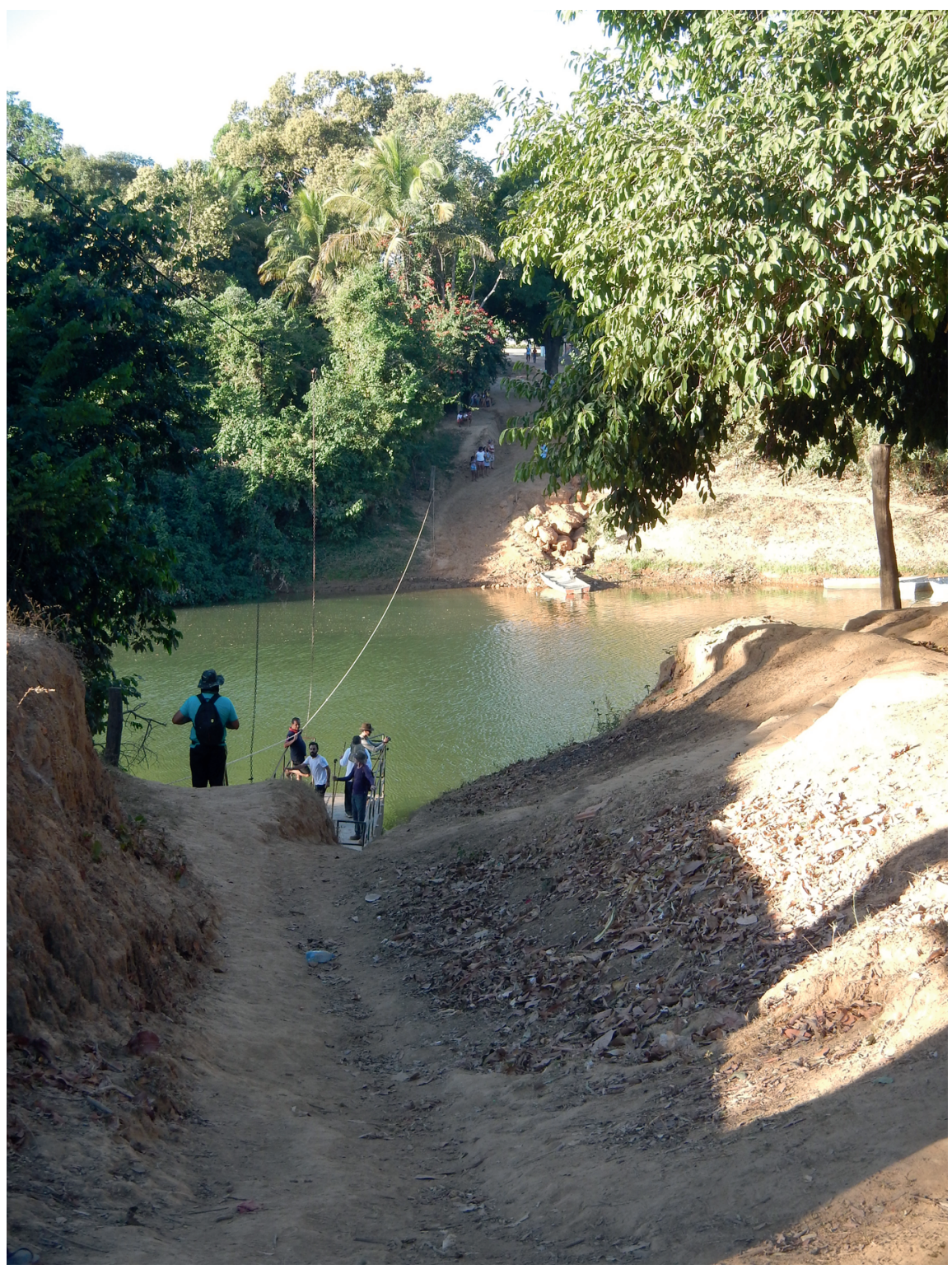

Abb. 1: Der Fluss Urucúia. Quelle: Willi Bolle 
2. Tag: Von Morrinhos bis zur Fazenda Menino. Unsere Wanderung begann mit der viele Kilometer langen Durchquerung einer riesigen Fazenda mit Pflanzungen von Mais und Bohnen. Hier, wie an so vielen anderen Stellen, hat man die ursprüngliche Cerrado-Waldung ganz und gar abgeholzt, um Platz für die Agrarindustrie zu schaffen (Abb. 2).

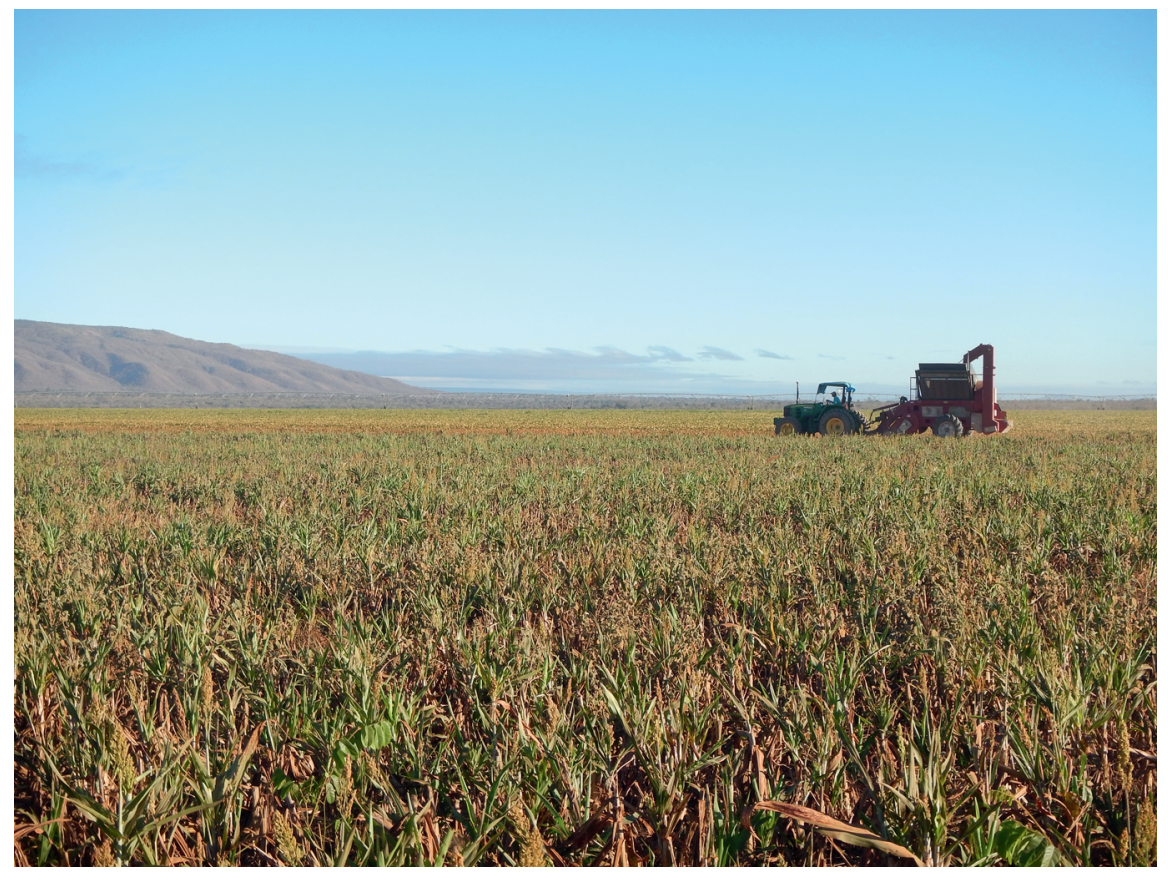

Abb. 2: Agrarindustrie. Quelle: Willi Bolle

Die drastischen Veränderungen der Umwelt werden von Almir Paraca, dem Leiter unserer Wanderung durch den Sertão, in einem im Dokumentarfilm Sertanías aufgezeichneten Interview wie folgt erklärt:

Das Problem, das sowohl die landwirtschaftlichen Kleinbetriebe wie die Agrarindustrie betrifft, ist das der Wasserversorgung. Das Wasser wird immer spärlicher, die Veredas vertrocknen, auch die Wasserläufe trocknen aus, die Regenfälle nehmen ab und der Grundwasserspiegel sinkt. $\mathrm{Zu}$ den Hauptursachen dieser Sachlage gehört die Art und Weise der Bewässerung, bei der eine übermäßige Menge von Wasser verbraucht wird. Die hier angewandten Methoden sind veraltet, es wird sehr viel Wasser verschwendet. Infolgedessen leiden viele der hiesigen Anwohner und Ortschaften unter Wassermangel. 
Einen Kontrast zu den ausgedehnten Fazendas der Agrarindustrie bieten die kleinbäuerlichen Familienbetrieb. Wir lernten den Eigentümer eines dieser Bauernhöfe kennen, Herrn Romualdo Rodrigues dos Santos, der im Film ebenfalls ein Interview gab:

Dieses Grundstück wurde als unproduktiv angesehen. Als wir hierher kamen, erhielten wir das Haus sowie elektrische Energie. Alles Übrige ist das Ergebnis der Arbeit von mir, meiner Frau und unseren zwei Söhnen. Wir hatten das Glück, hier angesiedelt zu werden. Wir leben einen gesunden Lebensstil und bereiten unsere Mahlzeiten auf einem Holzofen zu. Ich liebe diese Verhältnisse und deswegen wohne ich hier.

Unsere Wanderung an diesem zweiten Tag endete an der Fazenda Menino. Hier wurde in den 1950er Jahren unter Mitwirkung des Architekten Oscar Niemeyer die Schaffung einer großen Agrarkolonie geplant, die auch die damals im Bau befindliche neue Hauptstadt Brasília versorgen sollte. Das Projekt wurde jedoch nicht weitergeführt.

3. Tag: Von der Fazenda Menino bis zum Zusammenfluss des Ribeirão da Aldeia mit dem Ribeirão da Areia. Dieser Wasserlauf wird auch von dem Jagunço-Chef Riobaldo erwähnt, im Zusammenhang mit einem Plan, den er dann ein wenig später bekannt gibt: «Wir schlugen einen Haken und ritten am Ribeirão da Areia entlang. Was hatte ich im Sinn? Sie werden es gleich erfahren» (GS, S. 443). An diesem Tag durchquerten wir auch verschiedene Fazendas mit Rinderherden. Seit der Kolonialzeit ist die Rinderzucht die wirtschaftliche Haupttätigkeit im Sertão. Die Einrichtung der Fazendas führte auch zu zahlreichen Konflikten um Grund und Boden. Von einem dieser Fälle berichtet im Dokumentarfilm die Anwohnerin Cida Miranda:

\footnotetext{
Was meinen Lebensweg am stärksten geprägt hat, ist die Erfahrung des Kampfes. Meine Familie gehört zu denen, die um Grund und Boden kämpften. Der Vorwand für die Ermordung meines Vaters war eine Pflanzung, die er trotz der Anordnungen des Fazendeiro angelegt hatte. Dieser kam angeritten, begleitet von zwei Jagunços, die ebenfalls bewaffnet waren. Er wandte sich an meinen Vater und sagte: «Schauen Sie, Herr Júlio, Sie haben meinen Anweisungen zu Trotz eine Pflanzung angelegt. Nun werde ich das Problem Ihres Grundstücks noch heute für Sie regeln. Ich werde Euch alle zum Friedhof befördern». Und dabei zeigte er auf den dort drüben liegenden Friedhof. Gleichzeitig zog er seine Waffe, einen Revolver Kaliber 38, aus der Satteltasche und gab einen ersten Schuss ab. Meine Mutter eilte meinem Vater zu Hilfe. Da feuerte der Fazendeiro einen zweiten Schuss ab, der sie im Rücken traf. Sie fiel auf den Boden, und in diesem Moment schoss er zum tritten Mal. Dieser Schuss war fatal: Mein Vater starb auf der Stelle. Bis heute führen wir vor Gericht einen Kampf, um zu beweisen, dass dies alles eine große Ungerechtigkeit darstellt.
}

Die Jagunços gibt es bis heute; im Dienst der Großgrundbesitzer unterdrücken sie die Armen, die Landlosen. Im Roman von Guimarães Rosa wird das Jagunço-System als eine Parallelgesellschaft dargestellt. Zusätzlich zu den Schusswaffen können die lokalen Machthaber 
mit der Unterstützung von Abgeordneten und Senatoren rechnen, sowie mit der vom Staat geschaffenen Rechtsordnung.

4. Tag: Vom Ribeirão da Aldeia bis zu der Ortschaft Serra das Araras. Dies war ein Abschnitt des von Riobaldo gewählten Weges, der einen Überraschungsangriff auf die auf der anderen Seite der großen Wüste, im Staat von Bahia gelegene Fazenda des Erzfeindes Hermógenes vorhatte: «Nun sollen Sie wissen, was mein Plan war: Ich wollte die Sussuarão-Wüste durchqueren!» (GS, S. 457). Während unserer Wanderung kamen wir auch an schönen Veredas, d.h. an von Buritipalmen umsäumten Fließen vorbei (Siehe weiter unten Abb. 4).

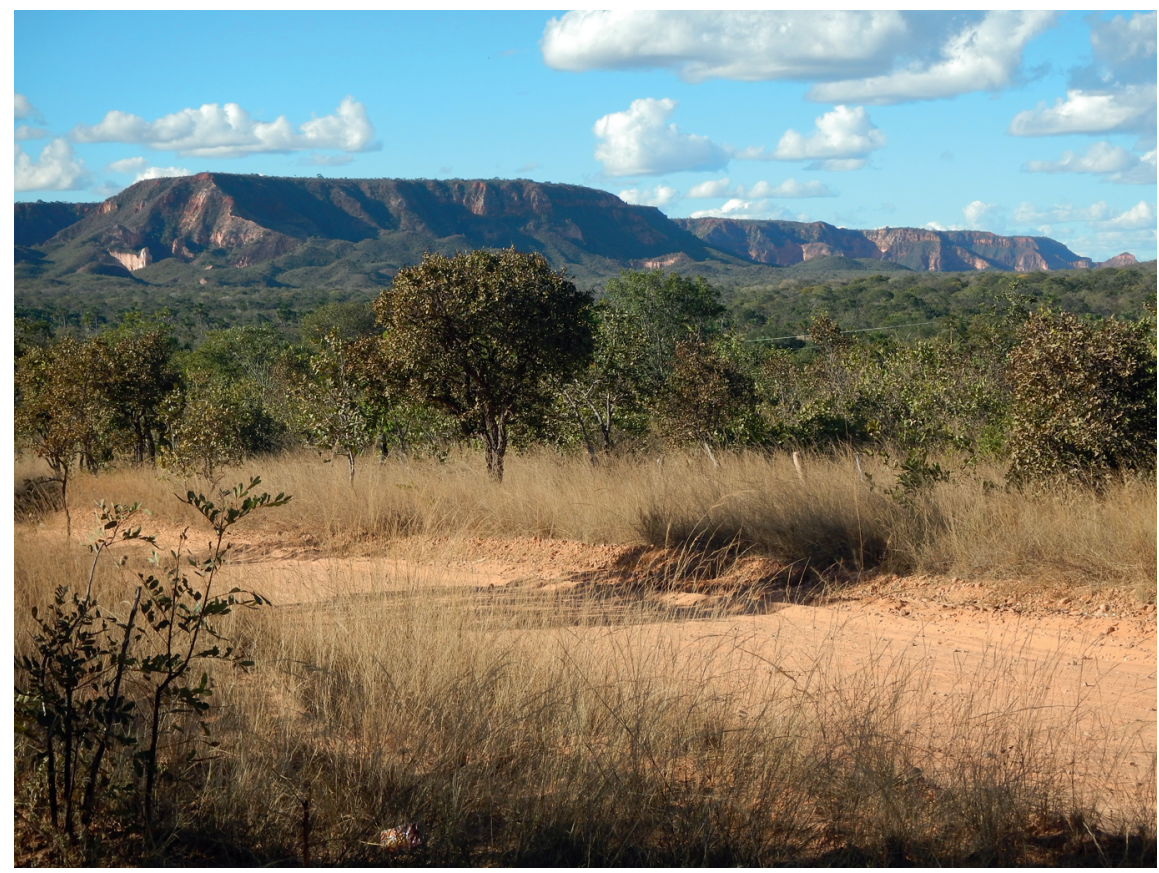

Abb. 3: Die Serra das Araras. Quelle: Willi Bolle

Sie erinnern uns an eine weitere Aussage von Riobaldo: «Ich werde Ihnen vom Sertão erzählen. Von dem ich nichts weiß. [...] Niemand kennt ihn noch. Nur eine Handvoll Leute - und nur die wenigen Veredas, die Fließe, die ich so liebe» (GS, S. 96). Am späten Nachmittag erreichten wir die Serra das Araras (Abb. 3), an der die gleichnamige Ortschaft liegt, in der wir übernachteten.

5. Tag: Von der Ortschaft Serra das Araras bis zu dem Flecken Barro Vermelho. Während einer Wanderung von $29 \mathrm{~km}$ lernten wir an diesem Tag einen großen 
Teil des im Jahre 1998 geschaffenen Naturschutzparks Serra das Araras kennen. Hier ist die ursprüngliche Vegetation des Cerrado noch erhalten. Wir durchquerten mehrere kleine Flüsse und Bäche, die in dieser Jahreszeit nahezu ausgetrocknet waren, und wanderten durch die Bergkette. Dabei begegneten wir verschiedenen Sertanejos, unter ihnen auch Jungen auf Pferden.

6. Tag: Von Barro Vermelho bis zu dem Städtchen Chapada Gaúcha. Am vorletzten Tag unserer Wanderung passierten wir den am Ufer des Rio Pardo gelegenen Ort Buraquinhos, mit einer schönen Aussicht auf die Landschaft. Danach erreichten wir den Flecken Vão dos Buracos. Riobaldo erwähnt diesen Ort, als die Jagunçobande unter Medeiro Vaz sich anschickt, «nach der Serra das Araras abzubiegen». Er erklärt seinem Zuhörer den Unterschied dieses Ortes im Vergleich mit der Sussuarão-Wüste: «Wie der Vão-do-Buraco? Nein, das ist was anderes» (GS, S. 36). Während seiner zweiten Durchquerung der Serra das Araras, schon als Bandenchef, erwähnt Riobaldo den Vão-do-Oco und den Vão-do-Cúio, «zwei abgrundtiefe Täler» (GS, S. 458), die sich möglicherweise auf die von uns berührten Orte beziehen. In Vão dos Buracos hat man eine Schule eingerichtet, mit einer gut organisierten Leseecke (Siehe Abb. 7 am Schluss dieses Aufsatzes).

Dort unterhielt ich mich mit der Lehrerin Rosa Amélia da Silva, die am Instituto Federal in Brasília unterrichtet und ebenfalls an unserer Wanderung teilnahm. In ihrem Buch Travessias literárias em perspectiva interacionista: teoria e prática (2016) beschreibt sie ihre Erfahrungen mit Lesezirkeln im Sertão am Urucúia. Ein Beispiel davon lernten wir am Ende des ersten Tages unser Wanderung in Morrinhos kennen, wo Rosa Amélia zusammen mit einer Gruppe von Anwohnern eine Inszenierung von Guimarães Rosas Erzählung Das dritte Ufer des Flusses vorgeführt hatte. In dem Dokumentarfilm Sertanías berichtet sie von der Bedeutung dieses Autors für die Bewohner des Sertão:

Das Werk von Guimarães Rosa führt einen intensiven Dialog mit der Erfahrung der Sertanejos. Die Schüler sind davon begeistert. Während der Lektüre der Texte fühlen sie sich angeregt, von ihren Erfahrungen und Erlebnissen und den Geschichten der Eltern, Großeltern und Tanten zu berichten. Guimarães Rosa hat den Bewohnern des Sertão einen Wert gegeben, von dem diese keine Ahnung hatten. Bekanntlich ist diese Region hier ohne Hilfe seitens der Regierung, ohne eine öffentliche Bildungspolitik, ganz und gar sich selbst überlassen. Und plötzlich erscheint ein Schriftsteller und widmet sich dieser Bevölkerung. Er zeigt der Welt, dass diese Sertanejos dieselben existentiellen Konflike leben wie die Menschen in allen übrigen Teilen der Welt.

Am Abend desselben Tages, nach einer Wanderung von $36 \mathrm{~km}$, erreichten wir das im Jahre 1976 von Bauern aus dem Staat Rio Grande do Sul gegründete Städtchen Chapada Gaúcha. Hier war ein großes Volksfest im Gange: das Treffen der Bewohner von Grande sertão veredas, das alljährlich gegen Ende der zweiten Juliwoche veranstaltet wird und im Jahre 2017 schon zum 16ten Mal stattfand. Während der 
Festtage werden auf dem zentralen Platz die verschiedensten Produkte aus dem Sertão vorgestellt, was eine konkrete Vorstellung der Kultur der Region vermittelt.

7. Tag: Von Chapada Gaúcha bis zum Eingang des Nationalparks Grande sertão: veredas, wo wir wiederum diese schönen, von Buritipalmen umsäumten Fließe bewundern konnten (Abb. 4).

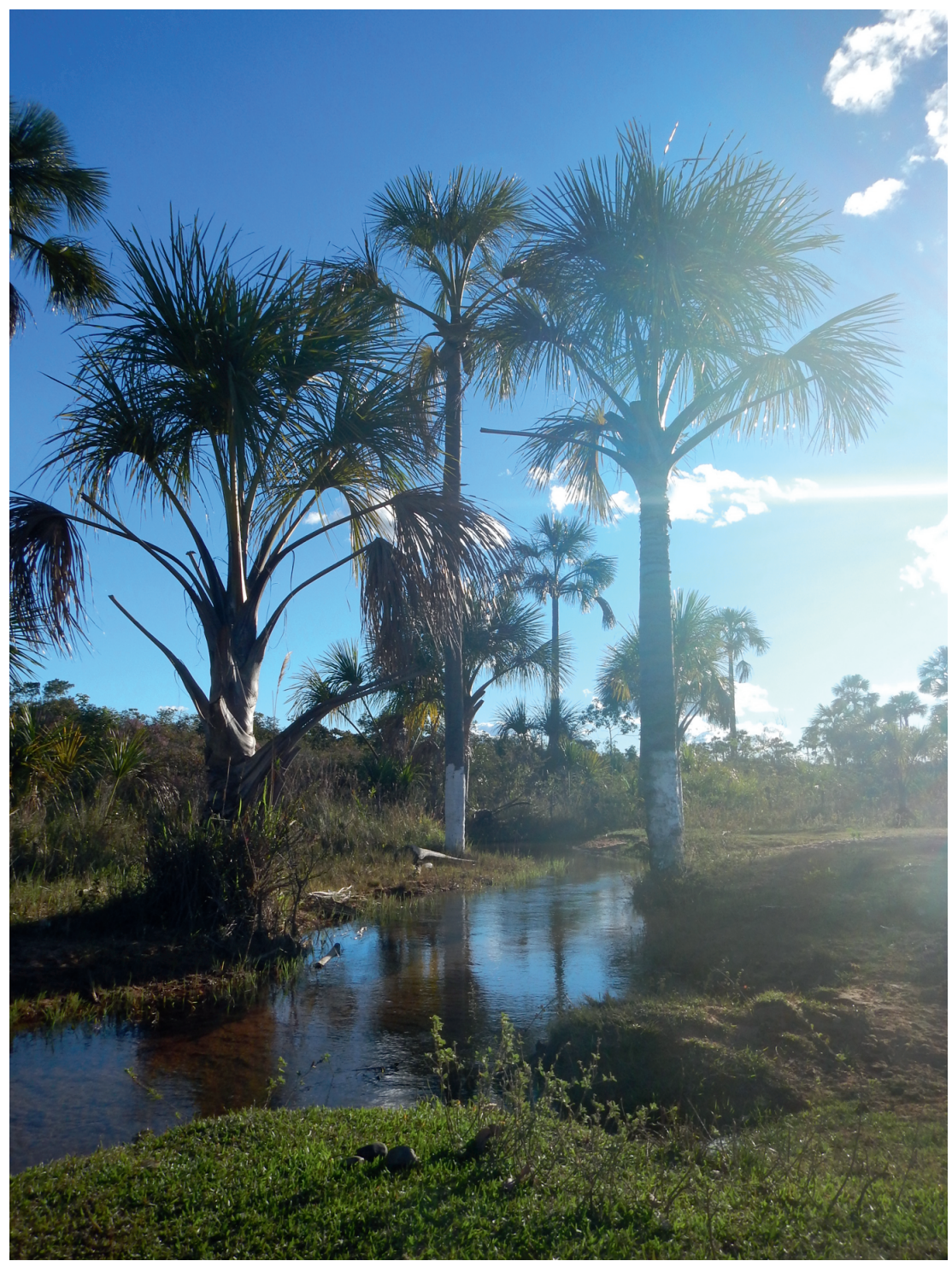

Abb. 4: Eine Vereda. Quelle: Willi Bolle 
Mit dieser Wanderung, $10 \mathrm{~km}$ hin und zurück, beendeten wir unsere Durchquerung des Sertão. Der Hauptzweck dieses im Jahre 1989 geschaffenen Parks mit einer Fläche von 230.000 Hektar ist die Erhaltung des Cerrado. Dieser ist nach dem Amazonas-Regenwald das zweitgrößte Biom Brasiliens und noch stärker von der Umweltzerstörung betroffen. «Zwischen 2000 und 2015 hat der Cerrado 236.000 $\mathrm{km}^{2}$ seines Waldbestands verloren, eine Fläche, die beinahe der Größe des Staates São Paulo entspricht.» ${ }^{14}$ Von der Aussichtsplattform am Eingang des Parks hat man einen Blick auf das Tal des Rio Carinhanha; jenseits davon beginnt, Riobaldo zufolge, die Sussuarão-Wüste.

\section{Vom heutigen Sertão zurück zum Roman als Brasilienbild}

Einige Orte und Momente unserer Wanderung regen dazu an, verschiedene Themen des Grande sertão: veredas zu kommentieren. Einer dieser Momente war der Bericht des Dichters Basílio Gomes Gonçalves aus Uauá im Nordosten von Bahia über die Aktualität des Krieges von Canudos. In dieser Ortschaft kam es im November 1896 zu einem ersten Gefecht zwischen den Anhängern des volkstümlichen Priesters Antônio Conselheiro und einem Infanterie-Bataillon des Staates. Basílio erinnerte an den Kampf der Sertanejos um bessere Lebensbedingungen und zitierte am Ende einen Satz aus seiner Denkschrift: «Die Geschichte wird der Figur des Antônio Conselheiro noch die gebührende Ehre erweisen». Er teilte uns auch mit, dass die Gruppe der Künstler, der er angehört, seit 2015 in jedem Jahr ebenfalls eine kollektive Wanderung veranstaltet und zwar von Uauá durch die Dürresteppe, die Caatinga, bis nach Canudos, dem Ort des im Oktober 1897 von der Armee brutal niedergeschlagenen Aufstands. Im März 2018 habe ich an dieser Wanderung teilgenommen, die nunmehr zum vierten Mal stattfand.

Da der wichtigste Bericht über den Krieg von Canudos sich in dem Buch Os Sertões (Krieg im Sertão) von Euclides da Cunha befindet, das auch eine eingehende Beschreibung des Landes und der dort wohnenden Menschen enthält, ist es aufschlussreich, dieses grundlegende Werk der «Brasilienbilder〉 mit dem Roman Grande sertão: veredas von Guimarães Rosa zu vergleichen, der als eine kritische réécriture jener ersten Darstellung interpretiert werden kann. Ein wesentlicher Aspekt für einen Vergleich ist die Perspektive, aus welcher der Sertão von jedem der beiden Schriftsteller dargestellt wird. In Os Sertões werden die Ereignisse häufig

14 Marcelo Leite: Bye bye cerrado. In: Folha de S. Paulo (12.11.2017), S. B9. 
«von oben` berichtet, von Orten wie Monte Santo oder der Favela-Höhe. Die Sertanejos werden aus einer auktorialen Perspektive vorgestellt, nur selten gibt Euclides da Cunha ihnen das Wort. In Grande sertão: veredas hingegen taucht der Erzähler Riobaldo, der «wie ein fließender Fluss denkt» (GS, S. 317), tief in die Sprache ein und in das Denken und Fühlen der Sertanejos. Damit erhebt sich auch die allgemeine Frage, wie das Volk von den brasilianischen Gebildeten dargestellt wird.

\section{Eine labyrinthische Form der Komposition}

Die beiden Perspektiven der Darstellung können wie folgt resümiert werden: Während Euclides da Cunha über den Sertão schreibt - indem er ihn als «terra ignota» und «silva horrida», und Canudos als eine «urbs monstruosa» charakterisiert, im Rahmen einer rationalistischen, progressistischen und linearen Geschichtsauffassung -, schreibt Guimarães Rosa wie der Sertão, d.h. in labyrinthischer Form. Die Komposition des Erzählens ist in erster Linie von der spontanen Erinnerung und den Gefühlen Riobaldos geprägt. Parallel dazu konstruiert der Autor ein wohlüberlegtes Netz des Erzählens, mit dem er die wichtigsten Themen organisiert: den Sertão, das Jagunçotum, den Pakt mit dem Teufel, die Liebe zwischen Riobaldo und Diadorim und die Darstellung des Volkes mittels seiner Sprache, der Hauptquelle von Guimarães Rosas Neuerfindung des Brasilianischen. Die Topographie der Handlungsorte ist ebenfalls labyrintisch, wie insbesondere anhand einer Karte gezeigt werden kann, die den Beginn der Geschichte des Jagunços Riobaldo, also seinen Ausschnitt in medias res (GS, S. 32-94; siehe Karte 5), resümiert. Der Weg des Protagonisten, der der Bande von Medeiro Vaz angehört, stellt eine Durchquerung des Sertão in allen Himmelsrichtungen dar, wie die folgenden vier Sequenzen der Episoden zeigen. 


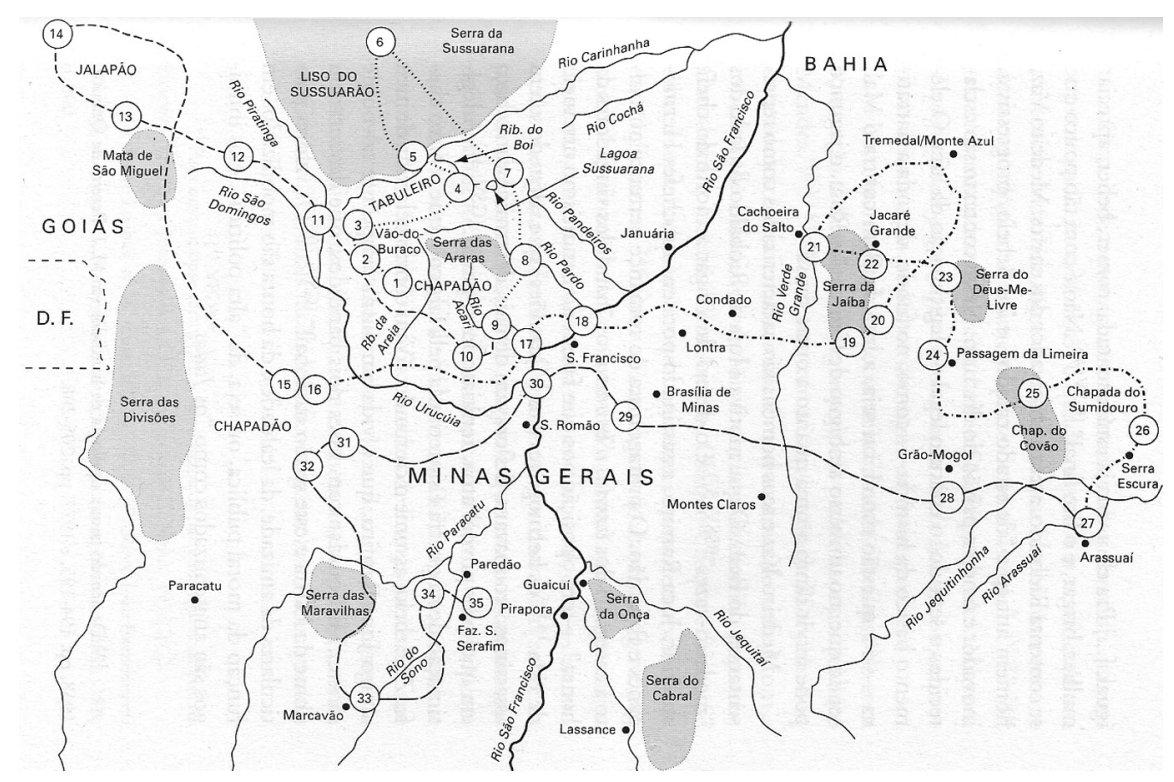

Karte 5: Topographie des Jagunçotums: in medias res

Vom Tafelland des Urucúia (1) reiten die Jagunços an der Serra das Araras (3) vorbei in Richtung Norden mit der Absicht, die Sussuarão-Wüste* (5 und 6) zu durchqueren; sie sehen sich jedoch gezwungen aufzugeben (6 und 7). - Um dem Angriff einer Truppe von Soldaten der Regierung nahe am Ribeirão do Acarí (9) zu entgehen, zieht sich die Bande zurück nach Westen, nach Goiás (13), bis zum Jalapão (14). - Um Kontakt mit verbündeten Banden aufzunehmen, wird Riobaldo von Medeiro Vaz in Richung Osten geschickt. An der «Salzstraße» zwischen Goiás und São Romão (16) entlang reitend, gelangt er an den Rio São Francisco (18), den er überquert und trifft dann in der Serra da Jaíba (19) mit dem Bandenchef João Goanhá zusammen. Nun beginnen jedoch neue Verfolgungen durch die Soldaten. Riobaldo zieht sich deswegen für einige Zeit aus dem Jagunçoleben zurück und arbeitet in den Edelsteinminen am Arassuaí (27). -

Danach reitet er wiederum in Richtung Westen, um sich erneut der Bande von Medeiro Vaz anzuschließen. Sein Weg führt ihn an den Städtchen Grão-Mogol (28) und Brasília de Minas (29) vorbei, er überquert den São Francisco (30) und erreicht schließlich das Tafelland des Urucúia (31). Beim Weiterritt in Richtung Süden, in dem Ort Marcavão* (33), stirbt Medeiro Vaz. Das Kommando der Bande wird von Zé Bebelo übernommen. Während seines Berichts von einem Schusswechsel bei der Fazenda São Serafim^ (35) erinnert sich Riobaldo an zwei für ihn traumatische Orte: Veredas Mortas und Paredão. Er unterbricht deshalb seine Erzählung. 


\section{Die Liebe zwischen Riobaldo und Diadorim}

An zwei Orten unserer Wanderung sahen wir zwei Skulpturen: Die eine davon zeigt die Überquerung des São Francisco von Riobaldo mit dem Jungen (Diadorim) (Abb. 5), die andere, seine Wiederbegegnung mit dem Jagunço Reinaldo.

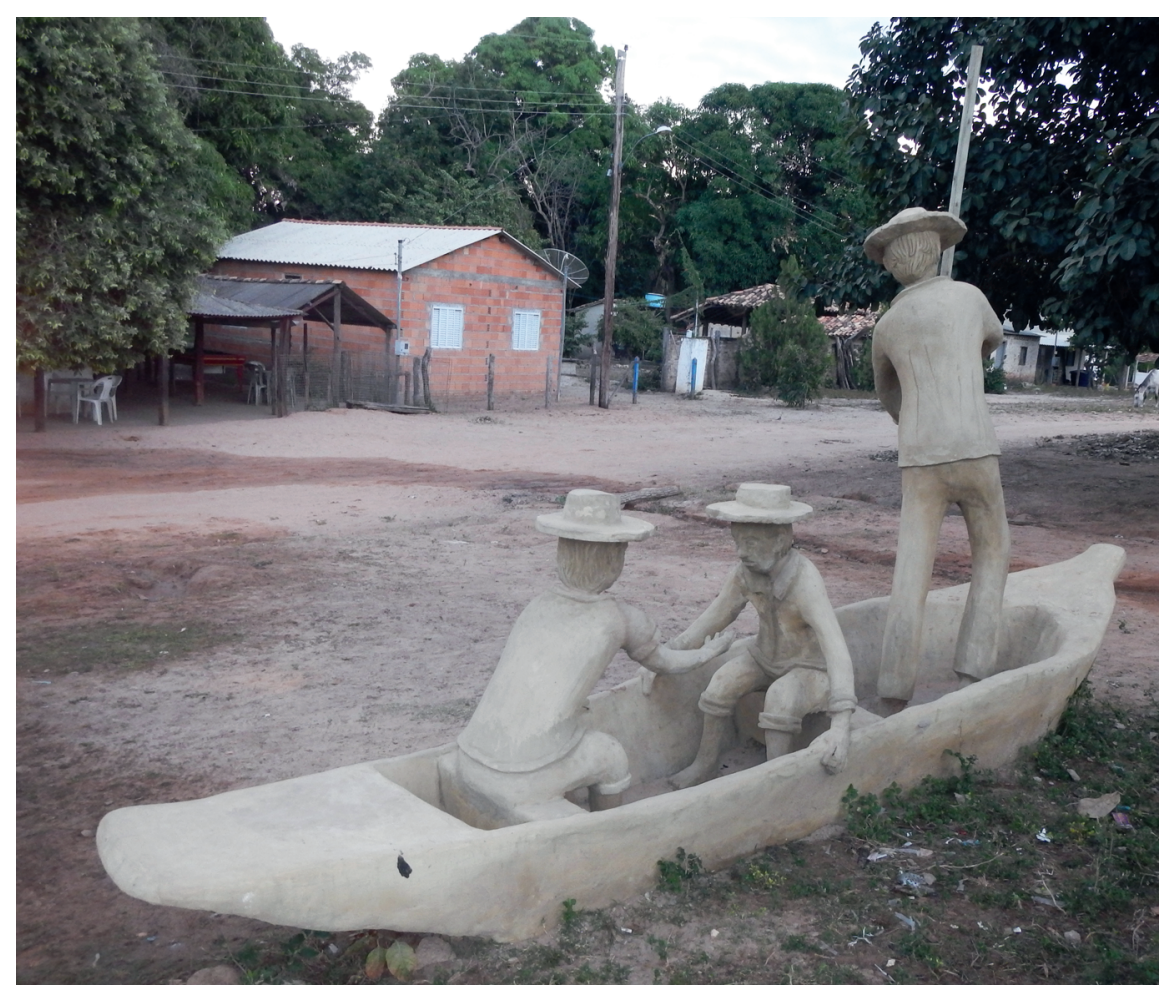

Abb. 5: Die Fluss-Überfahrt von Riobaldo mit dem Jungen Diadorim. Quelle: Willi Bolle

«Wenn Sie den kennen, kennen sie mein Leben» (GS, S. 295), erklärt Riobaldo. In der Tat: Diadorim ist das Leitmotiv seiner Geschichte. Wegen der Anziehung, die Diadorim auf ihn ausübt, hat Riobaldo sich entschlossen ein Jagunço zu werden. Da jedoch die Liebe zwischen zwei Männern in der machistischen Gesellschaft des Sertão ein Tabu war, hat Riobaldo sich zu dieser Liebe nicht offen bekannt. Als er dann Otacília, die Tochter eines Fazendeiro, kennenlernt, erwählt er diese zu seiner Braut, wobei er auch an sein Projekt eines gesellschaftlichen Aufstiegs denkt. Im Verlauf der Handlung identifiziert sich Diadorim immer mehr mit dem einfachen Volk, während Riobaldo hingegen sich davon entfernt. 


\section{Das Jagunço-System}

Ein Jagunço ist bekanntlich ein bewaffneter Mann im Dienste lokaler Machthaber, meistens Großgrundbesitzer, die sich damit eine Privatarmee schaffen. Ein konkretes Beispiel wurde in dem oben zitierten Bericht der Anwohnerin Cida Miranda genannt, deren Vater von einem Fazendeiro in Begleitung von zwei Jagunços ermordet wurde. Dennoch hatten einige der Teilnehmer an unserer Wanderung eine ganz andere Vorstellung von der Figur des Jagunços. In einem Bericht abends am Lagerfeuer idealisierte eine politische Aktivistin den Jagunço Riobaldo, indem sie ihn als einen Verteidiger der Belange der armen Sertanejos beschrieb. Ein irreführender Gebrauch des Wortes «Jagunço», obwohl mit einer ganz anderen Absicht, lässt sich auch bei Euclides da Cunha in seiner Darstellung des Kriegs von Canudos beobachten. Sein Bericht ist durch einen gravierenden Widerspruch gekennzeichnet. Einerseits beabsichtigt der Autor von Os Sertões, den Feldzug der Armee als «ein Verbrechen» zu denunzieren. Andererseits jedoch bezeichnet er die Anhänger des Antônio Conselheiro während seiner ganzen Darstellung als «Jagunços»; damit stuft er auch diese als Verbrecher ein und trägt dazu bei, die Vernichtung des politischen und sozialen Projekts von Canudos zu legitimieren.

Das Jagunçotum ist eines der Themen, anhand dessen sich klar zeigen lässt, dass Grande sertão: veredas eine kritische réécriture von Os Sertões ist. An keiner Stelle verfälscht Guimarães Rosa die Bedeutung des Wortes «Jagunço»; im Gegenteil: er stellt das Jagunçosystem in seiner ganzen Komplexität dar, aus allen möglichen Perspektiven, so wie es von den verschiedenen Romanfiguren wahrgenommen und erfahren wird. Riobaldo hört idealisierte und mystifizierende Erzählungen von Jagunçochefs, er nennt auch Beispiele von Entmystifizierung; er berichtet von seiner eigenen Einführung in das Jagunçotum und in die Praxis des Tötens, von seiner alltäglichen Erfahrung als einfacher Revolvermann, von den Kämpfen der Banden untereinander und gegen die Regierungstruppen, auch von der Ideologie, derzufolge das Jagunçotum einen Aufstand der Sertanejos gegen die Unterdrückung seitens der Regierung darstelle; in allen Einzelheiten zeigt Riobaldo das juristische und rhetorische System, welches das Jagunçotum als Institution unterstützt und zu rechtfertigen versucht; bald wird der Krieg der Banden als legitim dargestellt, bald werden die von den Jagunços begangenen Verbrechen verurteilt; die Entscheidung, ein Jagunço $\mathrm{zu}$ werden wird auch im Rahmen der weitverbreiteten Armut der Sertãobewohner gezeigt; und schließlich gibt der Protagonist und Erzähler zu erkennen, dass sein Aufstieg zu einem Jagunçochef ihm ermöglichte, seine einstigen Gefährten zu seinem eigenen Vorteil zu benutzen mit dem Ergebnis, dass er sich als ein mächtiger, von seinen Jagunços beschützter Großgrundbesitzer zur Ruhe setzten kann. Mit alldem präsentiert der Autor das Bild einer Gesellschaft, in der das Verbrechen ein fester Bestandteil 
des politischen und sozialen Systems ist und in weitem Umfang auf allen Ebenen praktiziert wird.

\section{Der Pakt mit dem Teufel: der Ort, die Motive und die Schuld}

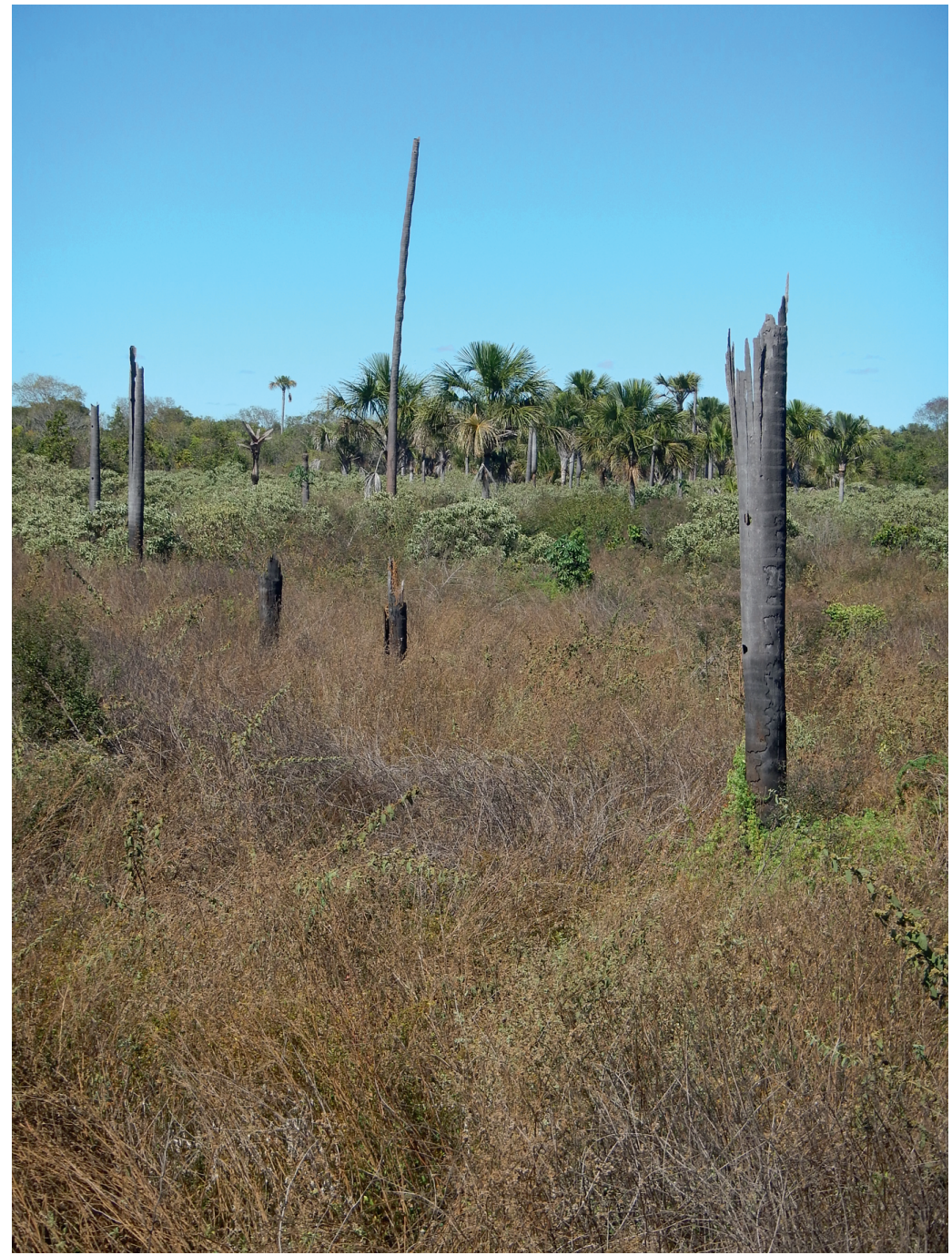

Abb. 6: Eine tote Vereda. Quelle: Willi Bolle 
An verschiedenen Orten unserer Wanderung kamen wir an toten Fließen, Veredas mortas, vorbei (Abb. 6). Das Vertrocknen der Veredas ist ein Ergebnis der Abholzung des Cerrado: seit den 1950er Jahren zur Gewinnung von Braunkohle und seit den 1980er Jahren zur Anlage von immer größeren Anbauflächen der Agrarindustrie, mit der Verschwendung riesiger Mengen von Wasser. Wir fühlten uns an die Veredas Mortas erinnert, den Ort, an dem Riobaldo den Pakt mit dem Teufel schloss (cf. GS, S. 383-388). Da die toten Fließe ein Ergebnis des Modernisierungsprozesses sind, erinnern wir uns auch an das Werk von Goethe, der in Faust II eine kritische Darstellung des technischen Fortschritts bietet, der zur Zerstörung der Umwelt führt. Zu Beginn des fünften und letzten Aktes wird in der Szene «Offene Gegend» mit den Gestalten von Philemon und Baucis, die in einer einfachen Hütte leben und den Wanderer aufnehmen, die vormals noch vollständig erhaltene Natur der früheren Zeiten evoziert. Im Gegensatz dazu wird dann in der Szene «Tiefe Nacht» von der Verbrennung der Hütte und der Beseitigung des Ehepaars und des Wanderers berichtet, die sich dem megalomanischen Projekt des Protagonisten und Teufelspaktierers widersetzten, der mit dem Bau von riesigen Deichen und Kanälen neue Flächen für die Kolonisierung schaffen wollte. ${ }^{15}$

Welches sind Riobaldos Motive, den Pakt mit dem Teufel zu schließen? In erster Linie der Plan, den Erzfeind Hermógenes, der den Ruf eines Teufelspaktierers hat (vgl. GS, S. 48-49), mit derselben Waffe zu besiegen. Ein weiterer Beweggrund ist der Wille, der bedrohlichen Situation zu entkommen, die durch die Begegnung mit dem Großgrundbesitzer Seô Habão entsteht. Dies ist der Kontext: Als Riobaldo zusammen mit seinen Jagunço-Gefährten unter Führung von Zé Bebelo an zwei Ortschaften tiefsten Elends ankommt, Pubo und Sucruiú, neben denen sich die Güter von Seô Habão befinden (vgl. GS, S. 352-355 und 377), wird er sich in der Begegnung mit diesem seiner wahren gesellschaftlichen Stellung bewusst: «Ich erkannte, dass ein Gutsbesitzer der endgültige Herr des Landes ist, während ein Jagunço nur provisorisch dahinlebt» (vgl. GS, S. 379). Als er spürt, wie der Fazendeiros ihn mustert, errät Riobaldo dessen Absicht: «Wir, Zé Bebelo, ich, Diadorim und alle anderen Kumpane sollten als Tagelöhner ihm beim Grasschneiden und Mähen, beim Säen und Ernten zur Hand gehen»; mit anderen Worten: «Seô Habão wollte uns zu seinen Leibeigenen machen!». Dagegen sträubt sich Riobaldo innerlich: «Wir als Roder und Hacker? Nie und nimmer!» (vgl. GS, S. 380-381). Noch am Abend desselben Tages macht er sich auf den Weg zu den Veredas Mortas, um den Pakt zu schließen (GS, S. 383).

15 Johann Wolfgang von Goethe: Faust: Der Tragödie erster und zweiter Teil. Urfaust. Hrsg. von Erich Trunz. München: C. H. Beck 1980, S. 333-335. Siehe Michael Jaeger: Wanderers Verstummen, Goethes Schweigen, Fausts Tragödie. Oder: Die große Transformation der Welt. Würzburg: Königshausen \& Neumann 2014. 
Es gibt noch einen dritten Beweggrund: Als Paktierer mit dem Teufel gelingt es Riobaldo, zum Chef der Bande aufzusteigen und die Jagunços zu seinem eigenen Nutzen zu verwenden. Sein erster Befehl lautet: «Bringt mir die Männer!», d.h. die Sertanejos von Sucruiú und Pubo. Dies wird sofort ausgeführt: «Sie brachten mir alle, die aufzutreiben waren». Seine Vorgehensweise - «Sie mussten mitkommen, mit sanfter Gewalt» - wird von dem neuen Kommandanten auf pseudo-moralistische Art kommentiert: «War das etwa boshaft von mir?» Er selber gibt darauf die scheinheilige Antwort: «Keineswegs - ich wollte sie alle nur aus ihrem Elend befreien» (GS, S. 404-405). Die demagogische Versprechung, die Riobaldo den neu rekrutierten Männern macht, ist ein Beispiel dafür, wie die Rhetorik des Jagunçosystems funktioniert:

- Wir werden hinausziehen in die Welt und denen, die etwas haben, ihr Geld und ihre Wertsachen wegnehmen. Und wir werden erst dann ruhen, wenn jeder hat was er braucht, wenn bei jedem von euch im Bett oder in der Hängematte zwei oder drei stramme Weiber liegen! (GS, S. 407)

Der Protagonist berichtet aber auch von seiner Schuld, so wie er es zu Beginn des zweiten Teils seiner Lebensgeschichte angekündigt hatte (GS, S. 290). Die Schuld wird nicht explizit dargelegt, sie steht zwischen den Zeilen. In Bezug auf Diadorim hatte Riobaldo wegen des gesellschaftlichen Tabus nicht den Mut, sich zu dieser Liebe offen zu bekennen. Er entschied sich für Otacília und erwählte sie zu seiner Braut. Die Heirat mit dieser Tochter eines Fazendeiro war sehr vorteilhaft für den sozialen Aufstieg Riobaldos und die Vergrößerung seiner Besitztümer. Den Teufelspaktierer Hermógenes hat nicht der Chef Riobaldo zu einem Duell gegen Mann gegen Mann herausgefordert, sondern Diadorim musste diese Aufgabe übernehmen und kam dabei uns Leben. Was die Beziehung zu seinen Jagunço-Gefährten betrifft, so hat Riobaldo sie von dem Moment an verraten, als er sich gegenüber Seô Habão als Sohn eines Gutsbesitzers und Obersten vorstellte (GS, S. 381). Als Kommandant hat er sie dann als Menschenmaterial benutzt, um Ruhm und Besitz zu erlangen.

Man könnte noch fragen: Welches ist die Glaubwürdigkeit dieses Erzählers, der einen Pakt mit dem «Vater der Lüge〉 geschlossen hat? Riobaldo ist vor allem ein dialektischer Erzähler. Indem er 〈die Formen des Falschen〉 darstellt, zeigt er zugleich, wie sie hergestellt werden. So z.B. ironisiert und kritisiert er die 〈Phrasendrescherei〉 des opportunistischen Zé Bebelo. Als Riobaldo dann aber selber das Kommando übernimmt, benutzt er genau dieselbe Art von demagogischen Sprüchen. 


\section{Gibt es eine Beziehung zwischen Riobaldos Pakt mit dem Teufel und dem schriftstellerischen Projekt von Guimarães Rosa?}

Anhand einiger Begriffe von Vilém Flussers Geschichte des Teufels (1993) möchte ich zeigen, dass im Roman von Guimarães Rosa eine diabolische und eine luziferische Funktion der Sprache zusammen wirken. ${ }^{16}$ "Als ich Grande Sertão schrieb», so erklärte er in einem Interview mit dem Kritiker Günter W. Lorenz, «musste meine Frau viel darunter leiden, denn ich war mit dem Buch verheiratet»; «Meine Sprache und ich sind ein Liebespaar, das eifrig miteinander zeugt.» ${ }^{17}$ Die Liebe des Schriftstellers zur Sprache ist, Flusser zufolge, eine diabolische Eigenschaft, eine sublimierte Form der Wollust. Als eine der sieben Todsünden infiziert die Wollust den Menschen mit anderen Hauptlastern, insbesondere mit Überheblichkeit oder Superbia.

Die Hauptambition des Schriftstellers João Guimarães Rosa bestand in der Neuschaffung oder Neuerfindung der Sprache, zumindest des brasilianischen Portugiesisch. Diesem Projekt liegt die Haltung zugrunde, mit Gott konkurrieren zu wollen, wie er in dem schon erwähnten Interview zugab: «Die Metaphysik meiner Sprache» bzw. «meine Sprache der Metaphysik» «ist im Grunde eine blasphemische Auffassung, denn sie macht den Menschen zum Herrn der Schöpfung». ${ }^{18}$ In einem Brief aus dem Jahre 1964 hat der Autor das Projekt seiner Sprachmächtigkeit wie folgt formuliert: «Ich will alles: die Sprache von Minas Gerais, das Brasilianische, das Portugiesische, das Lateinische - vielleicht sogar die Sprache der Eskimos und die der Tartaren. Ich will die vor Babel gesprochene Sprache.» ${ }^{19}$ Das ideale Ziel des Schriftstellers Guimarães Rosa wäre demnach die Schaffung einer universalen Sprache, in der virtuell alle Bewohner der Erde sich miteinander verständigen könnten.

16 Ich nehme hier einige Gedanken aus einem Aufsatz wieder auf. Vgl. Willi Bolle: Die luziferische Funktion der Sprache: Über Vilém Flusser und João Guimarães Rosa. In: Susanne Klengel/ Holger Siever (Hg.): Das Dritte Ufer: Vilém Flusser und Brasilien. Würzburg: Königshausen \& Neumann 2009, S. 63-79.

17 Günter W. Lorenz: Dialog mit Lateinamerika: Panorama einer Literatur der Zukunft. Tübingen/ Basel: Erdmann 1970, S. 510 und S. 516.

18 Lorenz: Dialog mit Lateinmerika, ebda.

19 Mary L. Daniel: João Guimarães Rosa: Travessia literária. Rio de Janeiro: José Olympio 1968, S. 26. 
Eine universale Sprache: dies aber würde bedeuten, die von Gott anlässlich des Turmbaus zu Babel verhängte Strafe der Sprachverwirrung und Inkommunikabiltät ${ }^{20}$ aufzuheben. Das Paradoxe an dieser Strafe ist, dass die Sprache erst durch das Eingreifen Gottes effektiv diabolisch, im etymologischen Sinne wurde. D. h. der Teufel - diábolos (von griechisch diabállein, «(sich) dazwischen werfen`) - stellt sich den Menschen in den Weg, die sich im Medium der Sprache miteinander verständigen wollen. Dies verweist uns auf den Kerngedanken von Friedrich Schlegels grundlegendem Aufsatz Über die Unverständlichkeit (1800). Ihm zufolge gibt es keine Garantie, dass die Verständigung der Menschen mittels der Sprache effektiv möglich ist. Denn neben allen guten Intentionen und der ehrlichen Suche nach Wahrheit ist die Sprache zugleich auch ein Werkzeug des Trugs und der Lüge, der Zweideutigkeit und der Missverständnisse, des Scheins, der Scheinheiligkeit, der Verstellung und der Maskierung. In der Beziehung zwischen Riobaldo und Diadorim kommt es - trotz der intensiven Zuneigung, die beide füreinander fühlen - zu verschiedenen Situationen des Einander-nichtVerstehens: verordnetes Schweigen, Abbruch des Dialogs, ein Missverstehen oder ein Missverstehen-Wollen, die Sprache als Ort eines bloßen Als-ob oder gar ihr Gebrauch als Waffe.

Grande sertão: veredas gilt allgemein als ein äußerst schwieriges Werk, geschrieben an der Grenze der Verständlichkeit. Diese Kompositionsform hat einen strategischen Grund. Die Erzählsituation und die Gestaltung des Erzählers als ein gebildeter Jagunço sind ironische Konstruktionen. Denn wo gibt es den Sachverhalt, dass ein gebildeter Mann aus der Stadt (der Zuhörer) sich die Zeit nimmt und die Geduld hat, einem ungebildeten Sertanejo über fünfhundert Seiten hinweg Gehör zu schenken? Mit dieser Konstruktion lenkt der Schriftsteller die Aufmerksamkeit auf den effektiv fehlenden Dialog im realen Brasilien zwischen dem Code der Gebildeten und der Sprache des einfachen Volkes. Das schriftstellerische, kulturelle und politische Projekt Guimarães Rosas zielt darauf, diese Situation mit dem Vorschlag einer neu zu schaffenden Sprache zu überwinden.

In diesem Sinne ist der Roman Grande sertão: veredas ein Labor für einen gesellschaftlichen Dialog, der in unserer Wirklichkeit noch nicht existiert. Jede Art von Diskurs wird dialektisch durch eine andere Form des Diskurses durchkreuzt. Vor allem aber können wir in jeder Zeile des Romans eine Zuversicht in die Macht der Sprache spüren, d.h. in das Vermögen jedes einzelnen Mitglieds der Sprachgemeinschaft, am Bau der Sprache als Gemeinwesen mitzuwirken. Mit anderen Worten: es handelt sich um ein Projekt, die diabolische Sprache - die der fehlen-

20 Vgl. Die Bibel. Übersetzung von Martin Luther. Stuttgart: Württembergische Bibelanstalt 1964. Genesis 11: 1-9. 
den Kommunikation - in eine rigoros luziferische Sprache, d.h. Licht tragende und Licht verbreitende, zu verwandeln. Die Tatsache, dass der Erzähler des Romans sich während der ganzen Zeit an einen gebildeten Zuhörer wendet, ist auch eine Aufforderung an uns, als Leser dieses Werkes, dass wir uns mit unserem Lese- und Schreibevermögen im Rahmen unserer Möglichkeiten in Tätigkeiten gesellschaftlicher Vermittlung engagieren. Die Orte, an denen dies in Brasilien am notwendigsten ist, sind zweifellos die öffentlichen Schulen, von denen wir auf unserer Wanderung ein Beispiel in dem Ort Vão dos Buracos kennengelernt haben. Zum Schluss zeige ich hier das Bild der Leseecke in jener Schule, weil es das war, was mich auf unserer Durchquerung des Sertão am meisten beeindruckt hat (Abb. 7). In Zusammenhang damit kommt mir die Erinnerung an den ErzählerProtagonisten von Grande sertão: veredas in jenem ganz besonderen Moment seines Lebens, als er «den Jüngeren Lesen und Schreiben beibrachte» (GS, S. 108).

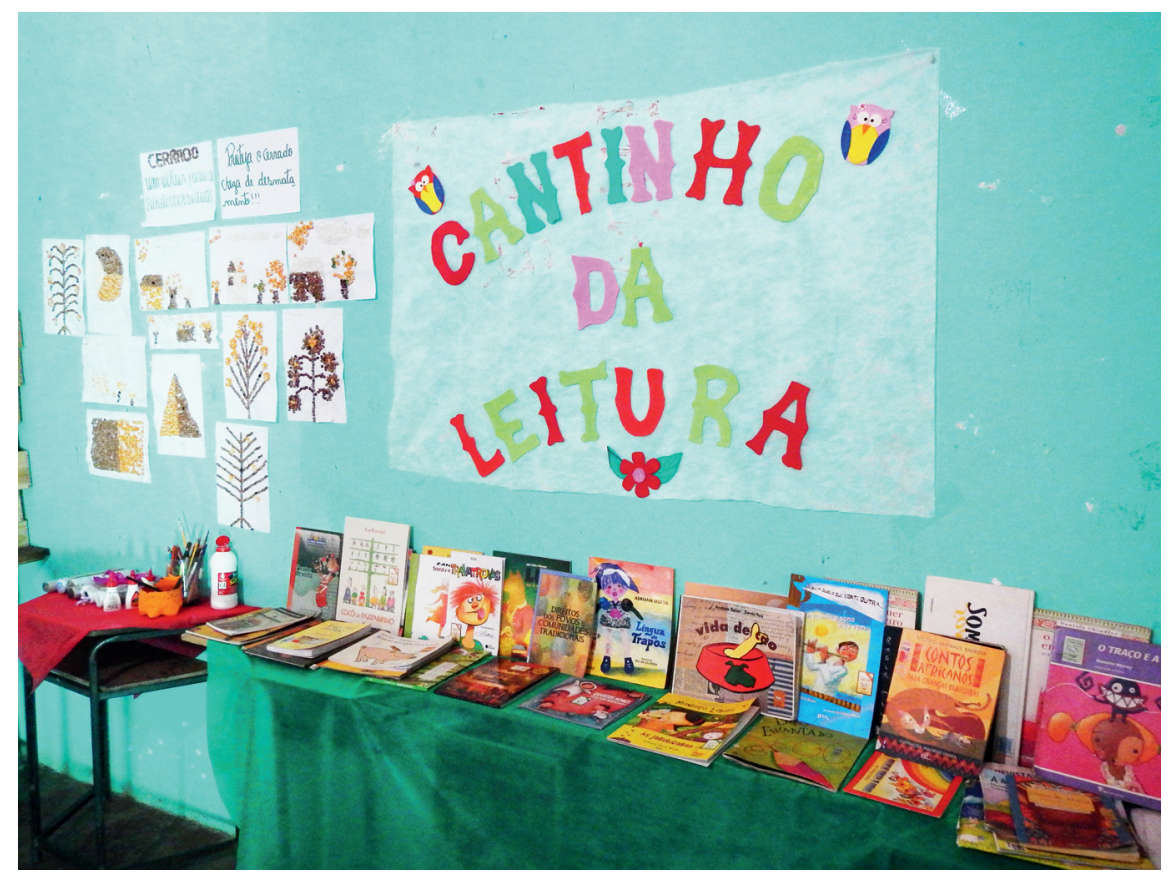

Abb. 7: Die Leseecke in der Schule von Vão dos Buracos. Quelle: Willi Bolle 
